\title{
Patient's dilemma for doctors to ponder over
}

\section{Dixit SM}

Sanjaya Mani Dixit, Lecturer, Department of Pharmacology, Kathmandu Medical College Teaching Hospital

W hen we are ill and anxious, we often face a dilemma which specialist one should see. If one is having lower back problem, does s/he go see an orthopaedic surgeon or a neurosurgeon or a nephrologist? Women with complaints in lower abdomen are unsure whether to take an appointment with a gastroenterologist or a gynaecologist. The dilemma in choosing the most appropriate specialist starts right away and does not end even when one gets to the hospital or clinic. The first hurdle is that not all the personnel at the hospital or nursing home counters are trained to identify patient's symptoms to be able to help steer the patients to right departments or specialists. Occasionally, the counter staff seems unsure when asked whom the patient should see and following a hurried chit-chat at the counter, advice to probably see a so and so specialist. Perhaps, the advisor at the back of his/her mind is confident that if the advice is wrong, then the specialist will steer the patient to the right place.

At times, we, as sufferers end up seeing a specialist who checks us for an illness under his/her specialty. The scenario gets a little complicated for elderly patients or for ones who suffer from multiple diseases when one is obliged to visit different specialists in different hospital or clinic. Specialists on finding that the patient does not have problem in the area of his/her expertise might refer to some other specialists. S/he might even announce that as the specific organ is fine and there is no need to worry about it. In such situation the resources and precious time for both is wasted. At the end, one is still unsure as to what the trouble is and who to see next?

It is good to have specialist doctors to take care of us when we fall ill, but is this era of specialization making doctors see the patients under specialist lens only? We are given medicines for different diseases by different specialists, but less is done to monitor the overall therapy the patient is receiving. We as patients are thereby

Address for correspondence

\section{Sanjaya Mani Dixit}

Lecturer, Department of Pharmacology

Kathmandu Medical College Teaching Hospital

E-mail: sanjayadixit@gmail.com treated in parts; and the adage - "Treat the patient and not the disease" is not being adhered to. Can this sort of treatment modality not lead to polypharmacy and prescription cascade, which is known to be relatively common in the elderly patients on multiple medications $^{1,2}$ ? Is patient safety a prime concern or is the aim just to keep the disease symptoms at bay ${ }^{3}$. No medico willingly takes responsibility for the medicines given to treat diseases that do not fall under ones' specialty. This is like trespassing on others property and signifies grey areas where doctors, like angels, fear to tread.

At times, when we as patients with pre-existing disease conditions, develop symptoms to a new malady unrelated to the earlier ones, we see a new specialist and are given certain advice which contradicts advice from the previous specialist. We and our families again face a new kind of dilemma as to what to do. Does one follow advice from the new specialist to treat the new disease or stick to the old one on whom we had been relying for years? Lack of multispecialty clinic approach in Nepal begins to hurt us more than ever before, for, in such a situation, the doctors do not have a single platform to interact with others for the best interest of the patient. One begins to question why one did not go in the first place to consultants in the same hospital setting? Had one chosen a single hospital with multiple specialties, would it not have been better? Was the decision to visit the best doctor in town inappropriate?

Going back to the dilemma in choosing a specialist, when we as patients are at loss as to who to see for a certain condition. Not all of us are fortunate to have family doctors, but we certainly have well wishers in our families, friends and neighbours. It is at this juncture that the laypersons, who are otherwise not knowledgeable in the field of medicine rise up to the occasion and start acting as consultants, briefing us as to what might the problem be and who would make the best doctor in town to visit.

This very concept of a best doctor has created another problem in that people wish to be seen by the best 
doctor in the field. For this desire,we sometimes need to book appointments even months in advance if not merely weeks. Even after getting to the specific doctor's clinic, we become surprised. Owing to the heavy patient load, best doctors usually assign young doctors who take history and other related information, get the preliminary investigations done, to help their chiefs. The chief then glosses over on the facts stated, cross questioning on a few instances, examining briefly and then moving on to make the final diagnosis and the treatment modalities.

In doing so, all three parties may be at loss. We as patients, after having waited for months to see the best doctor, only get a glimpse of the doctor and start questioning the concept of seeing the best, and at times ending being dissatisfied ${ }^{4}$ ? In contrast, the young doctors do not get due credit for getting the job done. $\mathrm{S} /$ he merely becomes the nameless and faceless aides to the best doctors they work for hoping to improve their practice, and waiting for their time to shine seems like forever. The best doctors, because of their fame, attract high patient load and therefore cannot give adequate time for the individual patient. This turns to mistrust of the patient, leading at times to miss many important aspects in relation to patient therapy.

Modern Nepal is developing more specialists with indepth knowledge in smaller fields of expertise. Doctors who can pin point the overall condition of the patient and treat patient as a whole are in decline. We do have general practitioners (GPs), who have done courses of MDGP, but sadly a very few hospitals have a department of general practice. This service should in fact be a compulsory component in every hospital and the Nepali population should be made aware of such services. Presently, patients feel that GPs are like doctors having no specific specialty and therefore choose to go to specialists directly. Some patients wrongly feel that they may be wasting time seeing a GP. More work needs to be done to ensure that people recognize the importance of the GP and develop a habit of seeing them first.

Another kind of dilemma the patient faces is the dilemma of under-diagnosis and under-treatment. Certainly treatment and communication related issues fall among the most pertinent patient complaints in diverse healthcare setting $\mathrm{s}^{5,6}$. People who can afford treatment in foreign countries face a dilemma as to whether to get treated in Nepal or to go abroad. It might also be one of the reasons that our politicians at top level go abroad for treatments which are otherwise easily available here.
It seems that a foreign jaunt is a facility provided by the state which politicians and the administrators seem to have an eye on. Is the therapy elsewhere better than here? Is it that we do not have hospitals which provide best services to the patient in terms of therapy? Our country had once floated the idea of Medical Tourism, but will the foreign tourists ever come with this type of service in Nepal?

Yes, Nepal is a country where until recent years the better performing students studied science. Almost 90 percent of those who studied biology majors wanted to study medicine. Many people in our healthcare sector studied abroad and returned to Nepal to serve the country. Some have even brought skills which Nepal did not have before. Though novel treatment methods like cataract surgery have developed here in Nepal, this sadly is a very rare instance. Even with doctors who have gained fame throughout the world, why is it that we have not been able to shine as a team, to provide assurance to our patients that you are in best hands and will get best treatment. Is it because our best doctors aren't adequate to offer the best treatments? Why is it that despite all this, people here are unsure if they can get best treatment within the country? How come we are still lagging behind in the field of medicine?

Some shortcomings in our society might be keeping us from being pioneers in the healthcare practice. We have the habit of putting the profession of doctors on a high pedestal, and looking down upon other professions as mediocres. Well, this attitude is not just that of doctors, but also exists in the civil servants. They too tend to look down on commoners as if they themselves were placed on high ground. They are indifferent to simple citizens. Could it all be attributed to our people who have the habit of calling out Maadsaab (Master Sahib) to the government officials and Daacsaab (Doctor sahib) to the doctors? If we only learn to see everyone as equal and believe that every profession has a responsible part to play in our society, then maybe we will stop raising any one to such a high level that they become accustomed to see others as being down trodden. Only then, will we look at different professionals working as a part of healthcare team with mutual respect for each other. Now that we have developed specialists for different fields of medicine, how come we have still not seen similar professional developments in the nurses, the pharmacists, the nutritionists, the microbiologists, the biochemists, et al. With team spirits elevated we could imagine leading the nation in healthcare practice too -engineers assisting doctors in using 3D printed organs 
and bones for surgery, pharmacists helping decreasing medication errors of different sorts. Geneticists helping cure genetic disorders and molecular biologists teaming up to work on stem cell projects in treatment of different diseases. If our country would lead in healthcare facilities, our citizens would not have to go abroad seeking proper diagnosis and treatment. We could rather envision Nepal in our lifetime leading towards Medical Tourism from the present stage of suboptimal diagnosis and therapy. Is it too much to dream for our nation?

\section{REFERENCES}

1. Nguyen PV, Spinelli C. Prescribing cascade in an elderly woman. Can Pharm J (Ott) [Internet]. 2016 May [cited 2017 Mar 23];149(3):122-4. Available from: http://www.ncbi.nlm.nih.gov/pubmed/27212961

2. Maher RL, Hanlon J, Hajjar ER. Clinical consequences of polypharmacy in elderly. Expert Opin Drug Saf [Internet]. 2014 Jan [cited 2017 Mar 23];13(1):5765. Available from: http://www.ncbi.nlm.nih.gov/ pubmed/24073682

3. Shekelle PG, Pronovost PJ, Wachter RM, Taylor $\mathrm{SL}$, Dy SM, Foy $\mathrm{R}$, et al. Advancing the Science of Patient Safety. Ann Intern Med [Internet]. 2011 May 17 [cited 2017 Mar 23];154(10):693. Available from: http://annals.org/article.aspx?d oi $=10.7326 / 0003-4819-154-10-201105170-00011$
4. Gross DA, Zyzanski SJ, Borawski EA, Cebul RD, Stange KC. Patient satisfaction with time spent with their physician. J Fam Pract [Internet]. 1998 Aug [cited 2017 Mar 23];47(2):133-7. Available from: http:// www.ncbi.nlm.nih.gov/pubmed/9722801

5. Reader TW, Gillespie A, Roberts J. Patient complaints in healthcare systems: a systematic review and coding taxonomy. BMJ Qual Saf [Internet]. 2014;23(8):67889. Available from: http://qualitysafety.bmj.com/ content $/ 23 / 8 / 678$

6. Punke H. 10 most common patient complaints, grievances with hospitals [Internet]. 2016 [cited 2017 Mar 23]. Available from: http://www. beckershospitalreview.com/quality/10-mostcommon-patient-complaints-grievances-withhospitals.html 